Check for updates

Cite this: RSC Adv., 2017, 7, 41585

Received 28th May 2017

Accepted 20th July 2017

DOI: 10.1039/c7ra05982e

rsc.li/rsc-advances

\title{
Magnetic nanoparticle modified chitosan for surface enhanced laser desorption/ionization mass spectrometry of surfactants $\dagger$
}

\author{
Hani Nasser Abdelhamid, ${ }^{\text {ab }}$ Yu Chih Lin $^{a}$ and Hui-Fen Wu (D) *acde
}

Chitosan (CTS) modified magnetic nanoparticles (CTS $a \mathrm{Fe}_{3} \mathrm{O}_{4} \mathrm{MNPs}$ ) offer dual functions for the detection of surfactants using surface enhanced laser desorption/ionization mass spectrometry (SELDI-MS). The characterization of $\mathrm{CTS} \mathrm{aFe}_{3} \mathrm{O}_{4}$ MNPs is carried out using X-ray diffraction, Fourier transform infrared spectroscopy, transmission electron microscopy, and UV-vis absorption. CTS $\mathrm{CFe}_{3} \mathrm{O}_{4}$ magnetic nanoparticles offer a simple separation method for surfactants. CTS@F $\mathrm{F}_{3} \mathrm{O}_{4}$ MNPs show an absorption band at $337 \mathrm{~nm}$ that matches the laser wavelength of the $\mathrm{N}_{2}$ laser. The material provides dual functionalities; as a probe and for surface enhanced LDI-MS. Analysis of surfactants using CTS@Fe $\mathrm{O}_{4}$ MNPs shows a remarkable limit of detection, offers high throughput analysis and fast separation ( $<5 \mathrm{~min})$. Compared to a conventional organic matrix (2,5-DHB), the spectra obtained using CTS $\left(\mathrm{Fe}_{3} \mathrm{O}_{4}\right.$ MNPs are interference-free. The interactions of the surfactants and $\mathrm{CTS}\left(\mathrm{Fe}_{3} \mathrm{O}_{4} \mathrm{MNPs}\right.$ are also investigated using FTIR and UV-vis absorption.

\section{Introduction}

Surfactants are widely used in many fields such as household detergents, hospitals, consumer products, capping agents for the synthesis of nanoparticles, natural dispersants (biosurfactants) that emulsify oil in water ${ }^{1}$ and clinical formulations. ${ }^{2}$ Several million tons of surfactants are produced every year. Over one million tons of anionic surfactants are being disposed of down the drain annually in the US alone. ${ }^{3}$ Surfactants interact with DNA, ${ }^{4}$ humic acids, ${ }^{5}$ the outer membrane of bacterial cells ${ }^{6}$ and other biomolecules. It was reported that the ecotoxicity of hospital wastewater identified detergents and disinfectants as the main causes of toxicity. ${ }^{7}$ Surfactants as capping agents of nanoparticles affect their cytotoxicities against human skin keratinocytes (HaCaT) and blood $\mathrm{T}$ lymphocytes (TIB-152). ${ }^{8}$ Thus, the detection or determination of these species are paramount important for human being. Concentration or distribution of surfactants have been followed

${ }^{a}$ Department of Chemistry, National Sun Yat-Sen University, Kaohsiung, 804, Taiwan. E-mail: hwu@faculty.nsysu.edu.tw; Fax: +886-7-525-3908; Tel: +886-7-525-2000 ext. 3955

${ }^{b}$ Department of Chemistry, Assuit University, Assuit, 71515, Egypt

'School of Pharmacy, College of Pharmacy, Kaohsiung Medical University, Kaohsiung, 800, Taiwan

${ }^{d}$ Institute of Medical Science and Technology, National Sun Yat-Sen University, Kaohsiung, 804, Taiwan

${ }^{e}$ Doctoral Degree Program in Marine Biotechnology, National Sun Yat-Sen University and Academia Sinica, Kaohsiung, 80424, Taiwan

$\dagger$ Electronic supplementary information (ESI) available. See DOI: 10.1039/c7ra05982e using liquid chromatography mass spectrometry (LC/MS/MS), ${ }^{3}$ methylene blue active substances (MBAS), ${ }^{9}$ capillary electrophoresis, ${ }^{10}$ and others. ${ }^{11}$ However, these methods require tedious procedures, show signal instability as well as requiring the use of large amounts of chlorinated solvents that are not readily biodegradable.

Matrix assisted laser desorption/ionization mass spectrometry (MALDI-MS) is a common analytical tool for the analysis of non-volatile compounds. ${ }^{12-16}$ It has been applied for the analysis of analytes such as proteins and their interactions, ${ }^{15,17,18}$ bacterial cells, ${ }^{19-22}$ fungi, ${ }^{23}$ metals, ${ }^{24,25}$ and others. ${ }^{26,27}$ Surprisingly, very few studies are available for the detection of surfactants using MALDI-MS. ${ }^{28}$ There are many challenges for the analysis of these species using conventional MALDI-MS. First, surfactants have small molecules and usually they undergo ion suppression due to the ions peaks of conventional organic matrices. Second, traditional organic matrices produce many interferences peaks. ${ }^{29}$ Third, surfactants are present in low concentration and that require a preconcentration step. ${ }^{3}$

Magnetite nanoparticles (e.g. iron oxide $\left(\mathrm{Fe}_{3} \mathrm{O}_{4}\right) \mathrm{MNPs}$ ) is a cubic inverse spinel structure with oxygen forming face centered cubic (fcc) close packing and Fe cations occupying interstitial tetrahedral sites and octahedral sites. ${ }^{30}$ Magnetic nanoparticles have been applied for biomedicine, ${ }^{31}$ catalysis, ${ }^{32-34}$ biotechnology included protein purification, drug delivery, medical imaging, ${ }^{35}$ environmental applications ${ }^{36}$ and as platforms for detection and separation applications. ${ }^{37,38}$ Magnetic nanoparticles and their modification were applied as adsorbent for removing methyl orange (MO, using chitosan/ $\mathrm{Al}_{2} \mathrm{O}_{3} /$ magnetic iron oxide nanoparticle), ${ }^{39}$ for the removal of 
$\mathrm{Hg}(\mathrm{II}),{ }^{40}$ aflatoxins, ${ }^{41}$ antidepressant drugs, ${ }^{42}$ endocrinedisrupting phenols ${ }^{\mathbf{4 3}}$ and others. ${ }^{\mathbf{4 4 , 4 5}}$ It has been applied to separate and enrichment of analytes; such as glycoproteins, ${ }^{46}$ phosphopeptides, ${ }^{47}$ endotoxins, ${ }^{48}$ biothiols, ${ }^{49}$ pathogenic bacteria $^{50}$ and others. ${ }^{51-53}$ Magnetic nanoparticles were used as probe for separation and enrichment of analytes. To the best of our knowledge, the preconcentration of surfactants using magnetic nanoparticles and MALDI-MS is not reported.

Herein, chitosan (CTS) modified magnetic nanoparticles (CTS@Fe $\mathrm{O}_{3} \mathrm{O}_{4} \mathrm{MNPs}$ ) was synthesized, characterized and applied as probe for the preconcentration of surfactants. CTS@ $\mathrm{Fe}_{3} \mathrm{O}_{4}$ MNPs was synthesized in basic medium using hydrothermal method. The synthesized nanoparticles were characterized using transmission electron microscopy (TEM), Fourier transform infrared (FTIR), X-ray diffraction (XRD), and UV-vis absorption. The particle size is less than $10 \mathrm{~nm}$. FTIR spectrum confirms the surface modification of $\mathrm{Fe}_{3} \mathrm{O}_{4}$ MNPs using chitosan. CTS@ $\mathrm{Fe}_{3} \mathrm{O}_{4}$ MNPs displays UV band absorption at $337 \mathrm{~nm}$ that matches with the $\mathrm{N}_{2}$ laser. Thus, CTS@ $\mathrm{Fe}_{3} \mathrm{O}_{4}$ MNPs offers potential application for surface enhanced laser desorption/ionization mass spectrometry (SELDI-MS). CTS@Fe $\mathrm{O}_{4}$ MNPs put forward multi-functional applications; probe for pre-concentration, matrix and surface for SELDI-MS.

\section{Materials and methods}

Chitosan (molecular weight $>75000 \mathrm{~g} \mathrm{~mol}^{-1}$, deacetylated > $75 \%$ ) was purchased from J.T. Baker (India). 2,5-DHB (2,5dihydroxybenzoic acid) was purchased from Alfa Aeser (Great Britain). Cetyltrimethyl ammonium bromide (CTAB), cetylpyridinium chloride monohydrates (CPC), sodium dodecyl benzene sulfonate (SDBS), and sodium stearate (SS), were purchased from Sigma Aldrich (USA). The de-ionized water obtained from Milli-Q Plus water purification system (Millipore, Bedford, MA, USA) was used for all experiments.

\section{Synthesis of chitosan modified magnetic nanoparticles (CTS@Fe $\mathrm{O}_{3}$ MNPs)}

Chitosan modified magnetic nanoparticles (CTS@ $\mathrm{Fe}_{3} \mathrm{O}_{4} \mathrm{MNPs}$ ) was synthesized using one pot method. ${ }^{54}$ Mixture of $\mathrm{FeCl}_{2} \cdot 4 \mathrm{H}_{2} \mathrm{O}$ $(0.63 \mathrm{~g})$, and $\mathrm{FeCl}_{3} \cdot 6 \mathrm{H}_{2} \mathrm{O}(1.73 \mathrm{~g})$ were mixed into chitosan solution ( $0.2 \mathrm{~g}, 25 \mathrm{~mL} \mathrm{H}_{2} \mathrm{O}, 1 \mathrm{~mL}$ acetic acid). The mixture was stirred for $12 \mathrm{~h}$ at room temperature. The $\mathrm{pH}$ of the solution was adjusted to 9 using $\mathrm{NH}_{4} \mathrm{OH}$ and was purged with nitrogen. The mixture was stirred in water bath at $90{ }^{\circ} \mathrm{C}$ for $3 \mathrm{~h}$. The precipitate was separated by external magnets and exhaustively washed with water $(2 \times 30 \mathrm{~mL})$.

\section{Instruments}

UV-vis absorption measurements of chitosan modified magnetic nanoparticles before and after interaction with surfactants were undertaken in a UV spectrophotometer (Perkin Elmer 100, Germany). Fourier transform infrared (FT-IR) spectra of chitosan modified magnetic nanoparticles before and after interaction with surfactants were recorded on FT-IR spectrometer (Spectrum 100, Perkin Elmer, USA). The particle size distributions of nanoparticles were determined using transmission electron microscope (TEM, JEOL-301, Tokyo, Japan). Matrix assisted laser desorption/ionization time of flight mass spectrometry (MALDI-TOF-MS) analysis were performed by employing positive mode on a time of flight mass spectrometer (Microflex, Daltonics Bruker, Bremen, Germany) with $1.25 \mathrm{~m}$ flight tube. Laser desorption/ionization mass spectrometry (LDI-MS) was obtained using $337 \mathrm{~nm}$ nitrogen laser with $3 \mathrm{~ns}$ pulse width. The accelerating potential in the source was maintained at $+20 \mathrm{kV}$. The laser power was adjusted to slightly above the ionization threshold to obtain good resolution and signal to noise ratios. The spectra were calibrated using DHB peaks (molecular weight is $154 \mathrm{~g} \mathrm{~mol}^{-1},[\mathrm{DHB}+\mathrm{Na}]^{+}$ at $177 \mathrm{Da}$ and $\left[\mathrm{DHB}-\mathrm{H}_{2} \mathrm{O}+\mathrm{H}\right]^{+}$at $\left.137 \mathrm{Da}\right)$. The experiments were repeated at least three times to confirm reproducibility. X-ray diffraction (XRD) was recorded using X-ray diffractometer (XRD, Philips, The Netherlands).

\section{Separation and preconcentration of surfactants}

Standard solution of surfactants; called cetyltrimethyl ammonium bromide (CTAB, $1 \mathrm{mM}$ ), cetylpyridinium chloride monohydrate (CPC, $1 \mathrm{mM}$ ), sodium dodecyl benzenesulfonate (SDBS, $1 \mathrm{mM}$ ), and sodium stearate (SS, $1 \mathrm{mM}$ ), were prepared in deionized water. Then, $\mathrm{CTS} @ \mathrm{Fe}_{3} \mathrm{O}_{4}$ magnetic nanoparticles (10 $\mu \mathrm{L}, 1 \mathrm{mg} \mathrm{mL}^{-1}$ ) were added to each solution of surfactant. The magnetic nanoparticles containing the surfactants were separated using external magnet. The separated species was redispersed in deionized water. Then, $2 \mu \mathrm{L}$ was spotted to MALDI plate for analysis.

Another $5 \mu \mathrm{L}$ of the separated species was also mixed with $5 \mu \mathrm{L}$ of DHB matrix solution (50 mM, $50: 50$ methanol : water (vol/vol)). Then, $2 \mu \mathrm{L}$ of the mixed solution was spotted in MALDI plate and leaved at room temperature for drying. Tape water was spiked with the surfactants and was analyzed suing the same protocol as mentioned above.

\section{Results and discussion}

\section{Material characterization}

Magnetic nanoparticles modified with chitosan (CTS@ $\mathrm{Fe}_{3} \mathrm{O}_{4}$ MNPs) are prepared by coordination of $\mathrm{Fe}^{2+}$ and $\mathrm{Fe}^{3+}$ ions in the backbone of chitosan before co-precipitation in basic medium. Chitosan function groups such as hydroxyl are important and can coordinate to the transition metal ions. Black magnetic nanoparticles are formed in basic solution under hydrothermal condition. Since the separation take placed using magnetic field, free chitosan would remain dispersed in the discarded aqueous phase and only that attached to the magnetic nanoparticles would appear in the final product. This method allows the collection of coated nanoparticles without free chitosan. The material is characterized using TEM (Fig. 1a), FTIR (Fig. 1b), UV-vis absorption (Fig. 1c), and XRD (Fig. 1d). TEM image of CTS@ $\mathrm{Fe}_{3} \mathrm{O}_{4}$ MNPs shows that magnetic nanoparticles embedded in the backbone of chitosan (Fig. 1a). Data show that the mean diameters ranging from 10 to $30 \mathrm{~nm}$. The interaction between chitosan and the surface of $\mathrm{Fe}_{3} \mathrm{O}_{4}$ MNPs is 

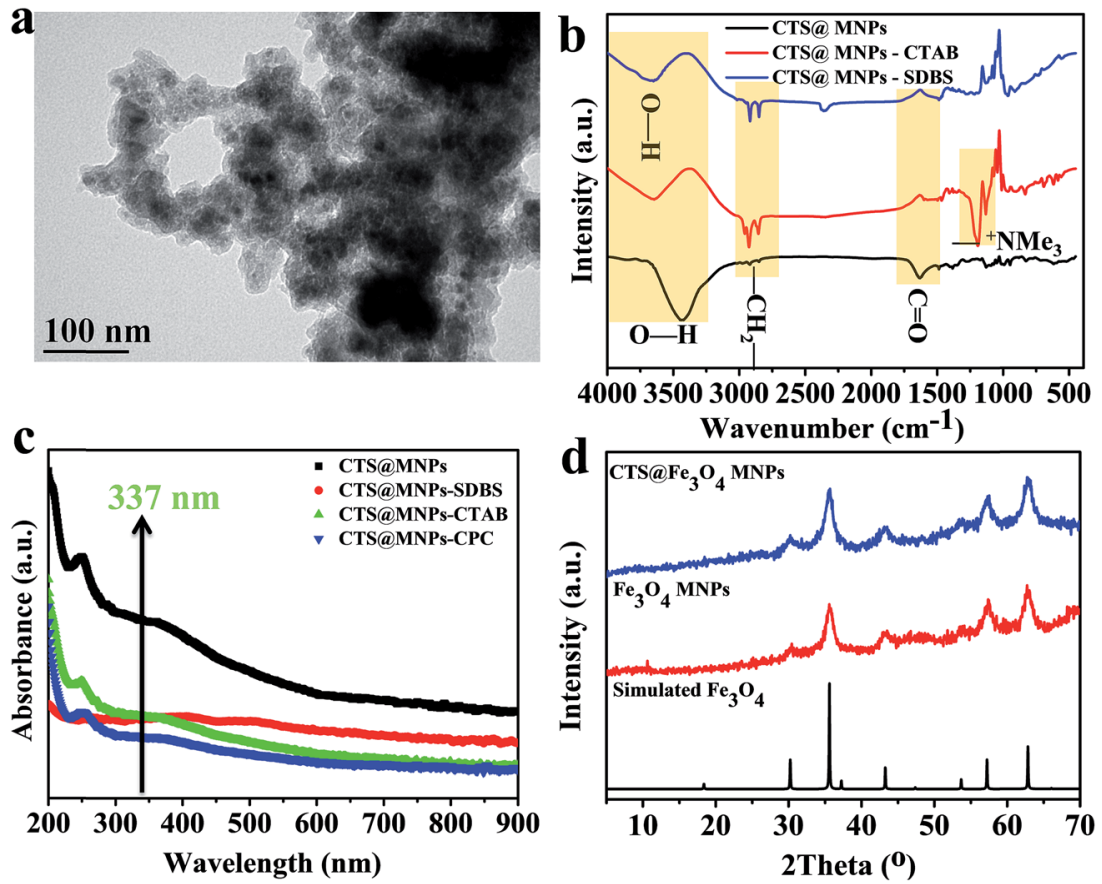

Fig. 1 Characterization of $\mathrm{CTS}\left(\mathrm{FFe}_{3} \mathrm{O}_{4}\right.$ MNPs using (a) TEM monograph, (b) FTIR and (c) UV-vis absorption and (d) XRD.

accomplished using FTIR spectra (Fig. 1b). The interaction takes place in many ways and is mainly based on dipole-dipole, hydrogen bond, or van der Waals interactions. The two bands at 2922 and $2850 \mathrm{~cm}^{-1}$ are attributed to the asymmetric of the methylene chains $\left(-\mathrm{CH}_{2}-\right)$ stretch and the symmetric $\mathrm{C}-\mathrm{H}$ stretch, respectively. The characteristic absorption bands for chitosan backbone was observed at 3450 (O-H stretching vibrations, a broad band), and a group of bands from 1100 to $1020 \mathrm{~cm}^{-1}$ (C-O-C and C-O stretching vibrations). The peak at $1660 \mathrm{~cm}^{-1}$ refers to $\mathrm{C}=\mathrm{O}$. UV-vis absorption of $\mathrm{CTS} @ \mathrm{Fe}_{3} \mathrm{O}_{4}$ MNPs was reported as shown in Fig. 1c. CTS@ $\mathrm{Fe}_{3} \mathrm{O}_{4} \mathrm{MNPs}$ displays absorption at $337 \mathrm{~nm}$ that matches with the wavelength of $\mathrm{N}_{2}$ laser of matrix assisted laser desorption/ionization mass spectrometry (MALDI-MS). XRD pattern shows good agreement of the experimental pattern with the simulated diffraction pattern (Fig. 1d). The patterns show no change after modification with chitosan (Fig. 1d).

\section{Principal of separation and detection of surfactants}

The synergic effect of the large surface area and the absorption at $337 \mathrm{~nm}$ (Fig. 1c) of CTS@ $\mathrm{Fe}_{3} \mathrm{O}_{4}$ MNPs reveal the promising applicability for SELDI-MS. Due to these two features i.e. absorption and large surface area, this technique can be coined as surface enhanced laser desorption/ionization mass spectrometry (SELDI-MS). Magnetic nanoparticles provide a simple probe for separation of target analytes. ${ }^{39-50}$ This character is highly required for preconcentration of the investigated analytes due to low concentration. In order to apply magnetic nanoparticles for species such as surfactants, the surface was modified with chitosan. General representation of the separation and detection of surfactants, called cetyltrimethyl ammonium bromide (CTAB), cetylpyridinium chloride monohydrate (CPC), sodium dodecyl benzenesulfonate (SDBS), and sodium stearate (SS), is presented in Fig. 2. CTS@ $\mathrm{Fe}_{3} \mathrm{O}_{4} \mathrm{MNPs}$ is added to the solution of the investigated surfactants. After few minutes $(<5 \mathrm{~min})$, external magnetic attracts the magnetic nanoparticles that have the target species. The separated particles are then deposited directly or after dispersion with a solution of conventional matrix " $2,5-\mathrm{DHB}$ ". The spots were desorbed and ionized using laser shots (337 nm). The chemical formula and the molecular weights of the investigated species are drawn as shown in Fig. S1. $\dagger$ The investigated species are small molecules with molecular weight less than 500 Da.

\section{Comparison of conventional organic matrix (MALDI-MS, 2,5- DHB) and CTS@Fe $\mathrm{O}_{4}$ MNPs (SELDI-MS)}

Laser desorption/ionization mass spectrometry (LDI-MS) is limited to analytes species that have absorption of laser energy. LDI-MS show no applicability for surfactants due to the absence of laser absorption. Thus, organic matrix such as 2,5-DHB is applied to the investigated analytes. However, self-ionization of the conventional matrix cause ion-suppression and their peaks complicate the spectrum. Hexadecyltrimethylammonium bromide (cetrimonium bromide) using DHB (Fig. 3) and CTS@Fe ${ }_{3} \mathrm{O}_{4}$ MNPs (Fig. 4) are compared. Spectra (Fig. 3, and 4) show peak at $285(\mathrm{~m} / \mathrm{z})$ corresponding to $\left[\mathrm{CH}_{3}\left(\mathrm{CH}_{2}\right)_{15}\left(\mathrm{CH}_{3}\right)_{3} \mathrm{~N}\right]^{+}$. CTS@ $\mathrm{Fe}_{3} \mathrm{O}_{4}$ MNPs (Fig. 4) shows no interference peaks compared to 2,5-DHB (Fig. 3). There is no observable peak related to chitosan backbone. Furthermore, CTS@ $\mathrm{Fe}_{3} \mathrm{O}_{4} \mathrm{MNPs}$ (Fig. 4) offers low limit of detection (LOD, 10 fmole) that is higher than sensitivity of 2,5-DHB (100 fmole, Fig. 3). The spectrum (Fig. 3b) shows peak at $m / z 137$ that assign as 


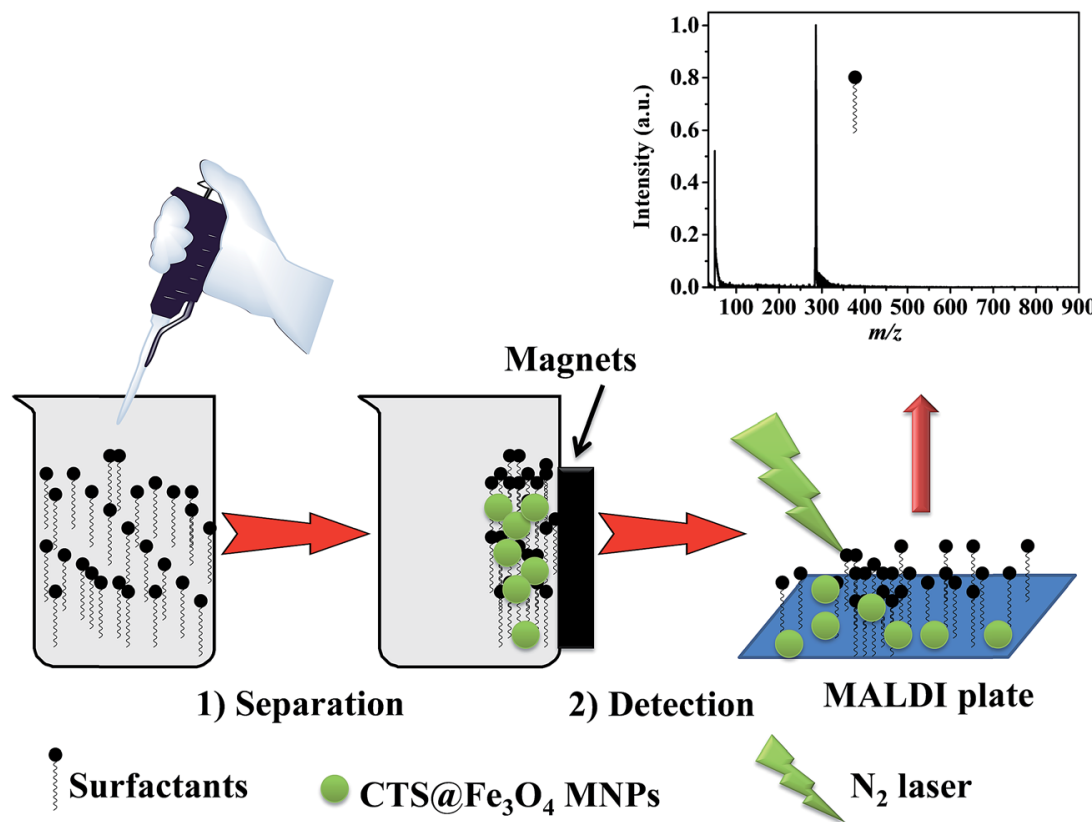

Fig. 2 Schematic representation of preconcentration of aqueous surfactants using CTS $\mathrm{FFe}_{3} \mathrm{O}_{4}$ MNPs prior to analysis using SELDI-MS.

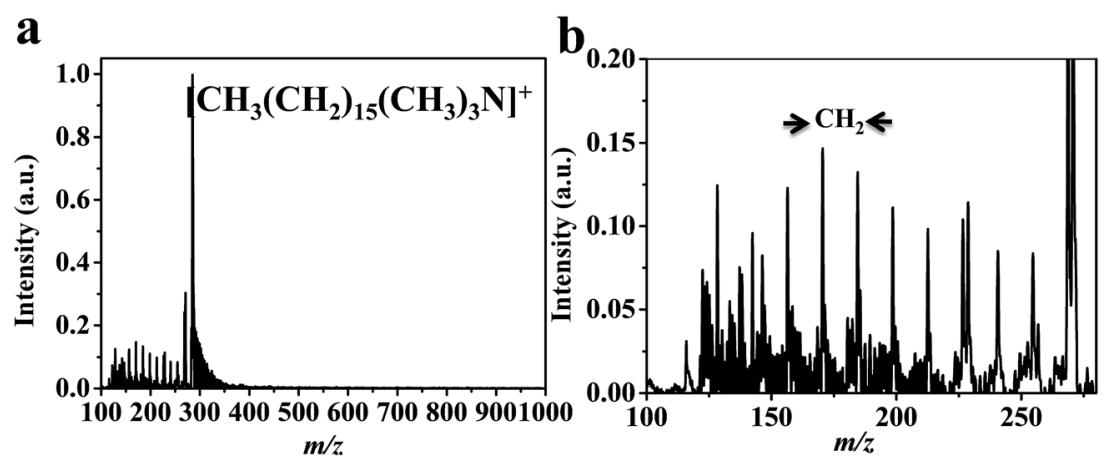

Fig. 3 MALDI-MS analysis of CTAB using 2,5-DHB.

$\left[\mathrm{DHB}-\mathrm{H}_{2} \mathrm{O}+\mathrm{H}\right]^{+}$. Zoom in the spectra of 2,5-DHB (Fig. 3b) and CTS@ $\mathrm{Fe}_{3} \mathrm{O}_{4}$ MNPs (Fig. 4b) show the degradation of the parent ion. The spectra show peak with difference equal to 14 Da corresponding to $-\mathrm{CH}_{2}-$ groups (Fig. $3 \mathrm{~b}$ and $4 \mathrm{~b}$ ). It was found that the detection of CTAB is useful method for internalization of nanoparticles into cells. ${ }^{55}$ Thus, the current protocol is promising for further applications in cells analysis.

\section{Sensitivity of CTS@ $\mathrm{Fe}_{3} \mathrm{O}_{4}$ MNPs for cationic and anionic surfactants}

CTS@ $\mathrm{Fe}_{3} \mathrm{O}_{4}$ MNPs has been applied for cetylpyridinium chloride monohydrate (CPC, Fig. 5), sodium dodecyl benzenesulfonate (SDBS, Fig. 6), and sodium stearate (SS, Fig. S2 $\dagger$ ). Spectrum of cetylpyridinium chloride monohydrate (CPC, Fig. 5) shows peak at $m / z 305$ corresponding to $\left[\mathrm{CPC}-\mathrm{Cl}-\mathrm{H}_{2} \mathrm{O}+\mathrm{H}\right]^{+}$. The spectrum (Fig. 5b) shows also peak at $\mathrm{m} / \mathrm{z} 610$ that is assigned as $[2 \mathrm{CPC}+\mathrm{H}]^{+}$. This peak indicates that laser desorption/ ionization using CTS@ $\mathrm{Fe}_{3} \mathrm{O}_{4}$ MNPs is soft ionization method.
Similar to CTAB (Fig. 4), CPC (Fig. 5) shows methylene groups $\left(-\mathrm{CH}_{2}-, 14 \mathrm{Da}\right)$ in the low mass range (50-280 Da). The peak of the parent ion $\left(\left[\mathrm{CPC}-\mathrm{Cl}-\mathrm{H}_{2} \mathrm{O}+\mathrm{H}\right]^{+}\right)$is shown in Fig. 5c. This peak confirms absence of chloride isotopes $\left({ }^{35} \mathrm{Cl}(75.78 \%)\right.$ and ${ }^{37} \mathrm{Cl}(24.22 \%)$ ). Sodium dodecylbenzenesulfonate (SDBS, Fig. 6) shows peaks at $m / z 348,233,364,156$ Da corresponding to $[\mathrm{SDBS}+\mathrm{Na}]^{+},\left[\mathrm{SDBS}-\mathrm{SO}_{3}+\mathrm{H}\right]^{+},[\mathrm{SDBS}+\mathrm{K}]^{+}$and $\left[\mathrm{C}_{11} \mathrm{H}_{24}\right]^{+}$, respectively. Spectrum of sodium stearate (SS, Fig. S2 $\dagger$ ) shows peaks at 306 and $322 \mathrm{Da}$ that are assigned as $[\mathrm{SS}+\mathrm{Na}]^{+}$ and $[\mathrm{SS}+\mathrm{Na}]^{+}$, respectively.

The mean concentrations of surfactants in tape water is very low. ${ }^{3}$ However, these low concentration can efficiently kill Gramnegative $E$. coli with a very low minimum inhibitory concentration $(1.70-0.93 \mu \mathrm{M}){ }^{6}{ }^{6}$ The lowest observed effective concentration of cetylpyridinium chloride (CPC) was $1.5 \mu \mathrm{M} .{ }^{56}$ The limit of detection (LOD) using 2,5-DHB and CTS@Fe $\mathrm{F}_{3} \mathrm{O}_{4}$ MNPs is 200 fmole and 50 fmole, respectively. The limit of detection for sodium dodecyl benzenesulfonate (SDBS, Fig. 6), and sodium stearate (SS, Fig. S2 $\dagger$ ) using CTS@ $@ \mathrm{Fe}_{3} \mathrm{O}_{4}$ MNPs is 10 fmole and 

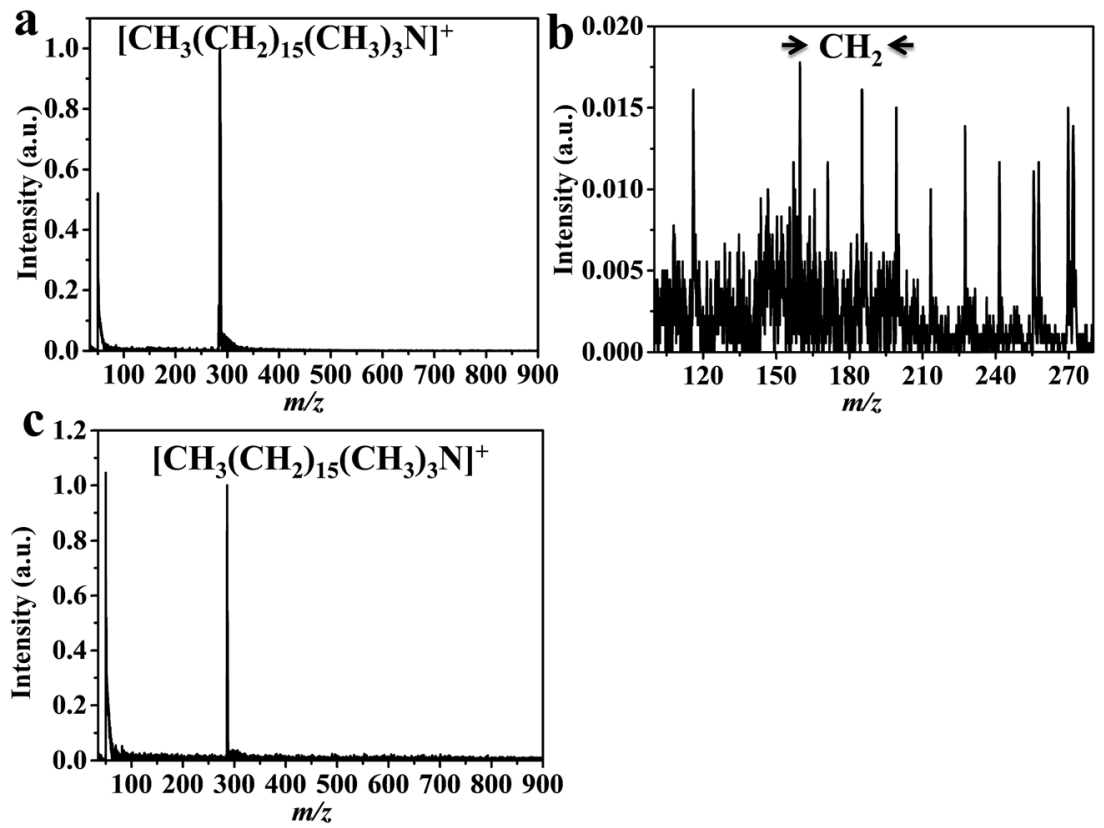

Fig. 4 SELDI-MS analysis of CTAB using $\mathrm{CTS} \mathrm{aFe}_{3} \mathrm{O}_{4} \mathrm{MNPs}_{\text {; }}(\mathrm{a})$ from deionized water and (b) represent the magnification of the spectrum in the range of $100-280 \mathrm{Da}$, and (c) the analysis of tape water.
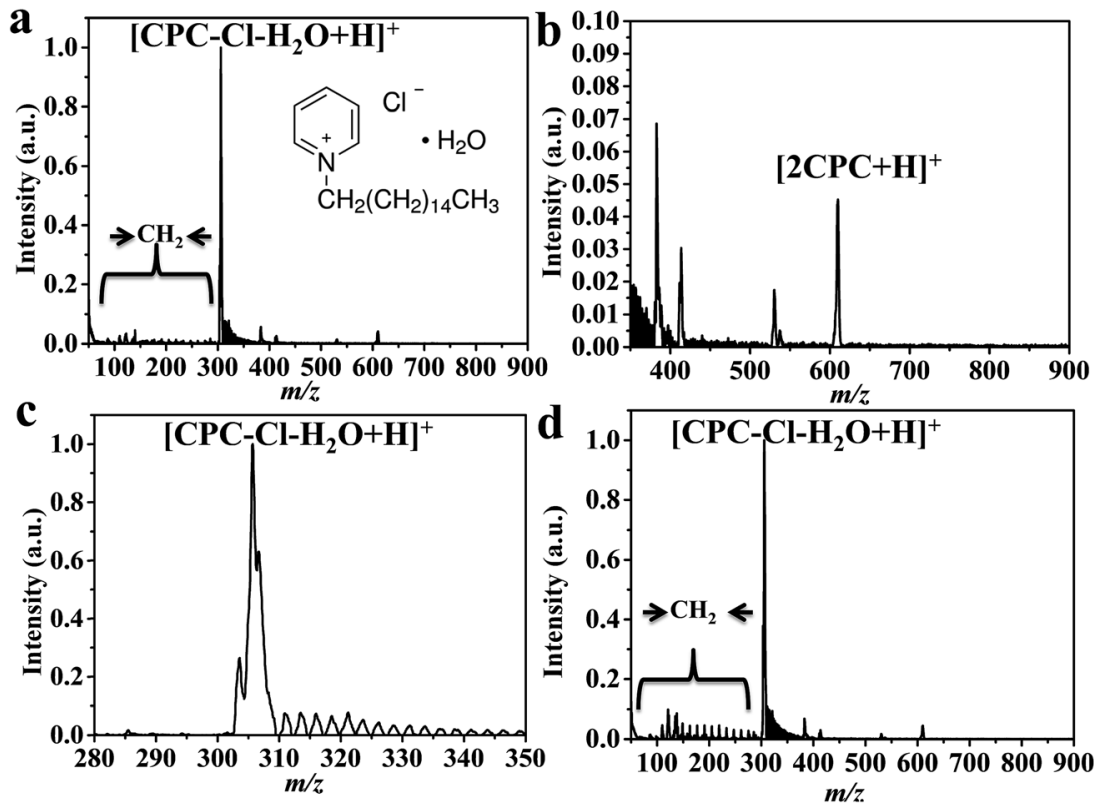

Fig. 5 SELDI-MS analysis of (a) CPC using CTS@Fe $\mathrm{O}_{4}$ MNPs; (b) magnification of the mass range of 350-900 Da, (c) the peak shape of the parent peak and (d) analysis of tape water.

20 fmole, respectively. These data indicate that the preconcentration of these species using CTS@ $\mathrm{Fe}_{3} \mathrm{O}_{4}$ MNPs is a sensitive approach. The separation takes place in few minutes $(<5 \mathrm{~min})$ and requires simple external magnets. CTS@ $\mathrm{Fe}_{3} \mathrm{O}_{4} \mathrm{MNPs}$ offers dual functions; probe for preconcentration and surface with special features (absorbance and large surface area). CTS@ $\mathrm{Fe}_{3} \mathrm{O}_{4}$ MNPs has large surface area and display absorption matches with the wavelength of $\mathrm{N}_{2}$ laser. These two features provide application for surface enhanced laser desorption ionization mass spectrometry (SELDI-MS). Thus, it provides low limit of detection, few interferences, higher resolution, and low fragmentations. These observations are confirmed from the analysis of tape water for CTAB (Fig. 4c) and CPC (Fig. 5d). The spectra show no background and display high resolutions.

\section{Selectivity and tape water analysis}

For real sample measurements, the four surfactants were mixed together in the tape water. They were mixed with the same 

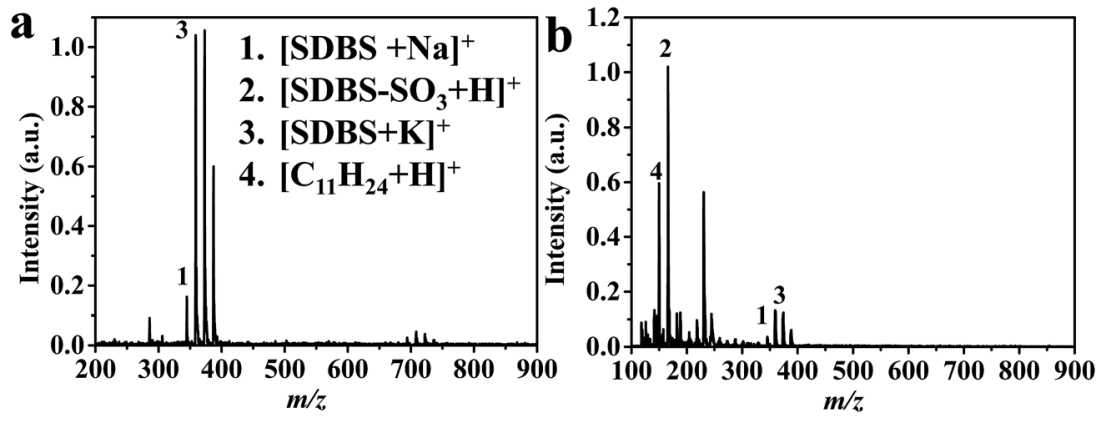

Fig. 6 SELDI-MS analysis of SDBS in (a) deionized water and (b) tape water.

concentration. Then, CTS@Fe $\mathrm{F}_{3} \mathrm{O}_{4}$ MNPs were applied to extract the species as the same for the standard samples (vide supra). Conventional matrix (2,5-DHB, Fig. S3 $\dagger$ ) and CTS@Fe $\mathrm{O}_{4} \mathrm{MNPs}$ (Fig. S4 $\dagger$ ) are compared. The spectra show mainly the peaks of CTAB ions. This may be because the high ionizability of this analytes compared to the other species. Conventional matrix (2,5-DHB, Fig. S3 $\dagger$ ) shows peak at $m / z 137$ that assign as $\left[\mathrm{DHB}-\mathrm{H}_{2} \mathrm{O}+\mathrm{H}\right]^{+}$. In contrast, CTS@ $\mathrm{Fe}_{3} \mathrm{O}_{4}$ MNPs (Fig. S4 $\dagger$ ) shows no interferences. It is also show higher resolution and very few fragmentation compared to conventional matrix i.e. 2,5-DHB. The limit of detection using 2,5-DHB and CTS@ $\mathrm{Fe}_{3} \mathrm{O}_{4}$ MNPs is 100 fmole and 200 fmole, respectively. The data indicate the high reproducibility of our method.

\section{Analysis of the interactions of surfactants and $\mathrm{CTS} @ \mathrm{Fe}_{3} \mathrm{O}_{4}$ MNPs}

The surface of magnetite NP's surface is either be O-rich or Ferich depending on the NP size. The presence of hydroxyl groups facilitates the modification of magnetic nanoparticles with chitosan. The functions groups of surface biomolecules i.e. chitosan are hydroxyl $(-\mathrm{OH})$, carbonyl $(\mathrm{C}=\mathrm{O})$, carboxylic $\left(-\mathrm{COO}^{-}\right)$and ammonium $\left({ }^{+} \mathrm{NH}_{3}\right)$. These groups assist the interaction of chitosan backbone with the target analytes such as surfactants. The interactions among CTS@ $\mathrm{Fe}_{3} \mathrm{O}_{4}$ MNPs and surfactants are evaluated using FTIR (Fig. 1b) and UV-vis absorption (Fig. 1c).

The interactions between CTS@ $\mathrm{Fe}_{3} \mathrm{O}_{4}$ MNPs surface and surfactants occur in many ways. The types of these interactions are mainly based on dipole-dipole, hydrogen bond, or van der Waals interactions. The two bands at 2922 and $2852 \mathrm{~cm}^{-1}$ are attributed to the asymmetric $-\mathrm{CH}_{2}-$ stretch and the symmetric $\mathrm{CH}$ stretch, respectively. These two peaks become sharp after the interaction with the investigated surfactants. These observations reveal the van der Waals interactions. The broad band at $1639 \mathrm{~cm}^{-1}$ is characteristic of the $\nu_{\left(\mathrm{COO}^{-}\right)}$. We didn't observe peaks related to $-\mathrm{NH}$ bending modes or any $-\mathrm{NH}_{2}$ wagging vibrations at $787 \mathrm{~cm}^{-1}$ in their FTIR data. However, after the interactions with $\mathrm{CTAB}$, the $-\mathrm{NH}_{2}$ wagging vibrations at $787 \mathrm{~cm}^{-1}$ is observed. The characteristic absorption band for chitosan modified magnetic nanoparticles (CTS@ $\mathrm{Fe}_{3} \mathrm{O}_{4} \mathrm{MNPs}$ ) at $3450 \mathrm{~cm}^{-1}$ (O-H stretching vibrations) shows shift to higher wavenumber $\left(3550 \mathrm{~cm}^{-1}\right)$. This observation is confirmed from the sharp peaks from 1100 to $1020 \mathrm{~cm}^{-1}$ (C-O-C and $\mathrm{C}-\mathrm{O}$ stretching vibrations). The presence of SDBS can be confirmed from the peak of $\mathrm{O}=\mathrm{S}=\mathrm{O}$ at $2250 \mathrm{~cm}^{-1}$. The peak at $1423 \mathrm{~cm}^{-1}$ is assigned to ammounium ions for CTAB.

The interactions of surfactants and CTS@Fe $\mathrm{O}_{4}$ MNPs were further investigated using UV-vis (Fig. 1c). Data show that the cationic surfactants cause no change in the absorption profile of CTS@ $\mathrm{Fe}_{3} \mathrm{O}_{4}$ MNPs. However, the absorbance decreases upon the interactions with $\mathrm{CTS} @ \mathrm{Fe}_{3} \mathrm{O}_{4}$ MNPs. It was found that bovine serum albumin (BSA) modified magnetic nanoparticles (MNPs-BSA) system was more stable in the presence of cationic surfactants. ${ }^{57}$ These interactions may assist separation and improve the analysis of SELDI-MS.

\section{Conclusions}

We successfully reported the applications of chitosan modified magnetic nanoparticles (CTS@ $@ \mathrm{Fe}_{3} \mathrm{O}_{4} \mathrm{MNPs}$ ) for preconcentration and detection of surfactants (cationic and anionic). The method utilizes the unique properties of CTS@ $\mathrm{Fe}_{3} \mathrm{O}_{4} \mathrm{MNPs}$ including high surface area, supermagnetism causing rapid separation $(<5 \mathrm{~min})$ and high absorbance matches at $\mathrm{N}_{2}$ wavelength $(337 \mathrm{~nm})$. Further investigation demonstrates that the presence of various surfactants on the surface of CTS@ $\mathrm{Fe}_{3} \mathrm{O}_{4}$ MNPs affects the optical properties. However, surface enhanced laser desorption ionization mass spectrometry (SELDI-MS) using CTS@ $\mathrm{Fe}_{3} \mathrm{O}_{4}$ MNPs effectively ionize these species in deionized and tape water. CTS@ $\mathrm{Fe}_{3} \mathrm{O}_{4}$ MNPs offered dual functions; probe for preconcentration and matrix. These results may open a new venue for further applications for environmental and biomedical concerns.

\section{Conflicts of interest}

There are no conflicts to declare.

\section{Acknowledgements}

We acknowledge the financial support from the Ministry of science and technology Taiwan. H. N. Abdelhamid expresses his gratitude to Assuit University and Ministry of Higher Education (Egypt) for support. 


\section{References}

1 S. Kleindienst, J. H. Paul and S. B. Joye, Nat. Rev. Microbiol., 2015, 13, 388-396.

2 Y. Zhang, W. Song, J. Geng, U. Chitgupi, H. Unsal, J. Federizon, J. Rzayev, D. K. Sukumaran, P. Alexandridis and J. F. Lovell, Nat. Commun., 2016, 7, 11649.

3 K. McDonough, K. Casteel, N. Itrich, J. Menzies, S. Belanger, K. Wehmeyer and T. Federle, Sci. Total Environ., 2016, 572, 434-441.

4 Q. Guo, Z. Zhang, Y. Song, S. Liu, W. Gao, H. Qiao, L. Guo and J. Wang, Chemosphere, 2016, 168, 599-605.

5 R. D. Deese, M. R. LeBlanc and R. L. Cook, Environ. Chem., 2015, 13, 507-516.

6 C. Zhou, F. Wang, H. Chen, M. Li, F. Qiao, Z. Liu, Y. Hou, C. Wu, Y. Fan, L. Liu, S. Wang and Y. Wang, ACS Appl. Mater. Interfaces, 2016, 8, 4242-4249.

7 C. Boillot and Y. Perrodin, Ecotoxicol. Environ. Saf., 2008, 71, 252-259.

8 Y. Zhang, X. Li and H. Yu, J. Environ. Sci. Health, Part C: Environ. Carcinog. Ecotoxicol. Rev., 2016, 34, 204-215.

9 A. D. Eaton, L. S. Clesceri, A. E. Greenberg and M. A. H. Franson, American Public Health Association, American Water Works Association and Water Environment Federation, Standard methods for the examination of water and wastewater, American Public Health Association, Washington DC, 1998.

10 K. Heinig and C. Vogt, Electrophoresis, 1999, 20, 3311-3328. 11 S. Hussain, A. H. Malik and P. K. Iyer, ACS Appl. Mater. Interfaces, 2015, 7, 3189-3198.

12 H. N. Abdelhamid, TrAC, Trends Anal. Chem., 2017, 89, 6898.

13 H. N. Abdelhamid and H.-F. Wu, Anal. Bioanal. Chem., 2016, 408, 4485-4502.

14 H. N. Abdelhamid and H.-F. Wu, TrAC, Trends Anal. Chem., 2014, 65, 30-46.

15 H. F. Wu, J. Gopal, H. N. Abdelhamid and N. Hasan, Proteomics, 2012, 12, 2949-2961.

16 H. N. Abdelhamid, TrAC, Trends Anal. Chem., 2016, 77, 122138.

17 H. N. Abdelhamid and H.-F. Wu, Anal. Bioanal. Chem., 2016, 408, 4485-4502.

18 H. N. Abdelhamid and H.-F. Wu, Analyst, 2015, 140, 15551565.

19 H. N. Abdelhamid, M. L. Bhaisare and H.-F. Wu, Talanta, 2014, 120, 208-217.

20 H. N. Abdelhamid, J. Gopal and H. F. Wu, Anal. Chim. Acta, 2013, 767, 104-111.

21 B.-S. Wu, H. N. Abdelhamid and H.-F. Wu, RSC Adv., 2014, 4, 3722-3731.

22 B. Li, T. J. Comi, T. Si, S. J. B. Dunham and J. V. Sweedler, J. Mass Spectrom., 2016, 51, 1030-1035.

23 H. N. Abdelhamid, S. Kumaran and H.-F. Wu, RSC Adv., 2016, 6, 97629-97635.

24 H. N. Abdelhamid and H.-F. Wu, RSC Adv., 2015, 5, 7610776115.
25 H. N. Abdelhamid and H.-F. Wu, J. Am. Soc. Mass Spectrom., 2014, 25, 861-868.

26 H. N. Abdelhamid, A. Talib and H.-F. Wu, Talanta, 2016, 166, 357-363.

27 H. N. Abdelhamid and H. F. Wu, Microchim. Acta, 2017, 184, 1517-1527.

28 H. N. Abdelhamid, B.-S. Wu and H.-F. Wu, Talanta, 2014, 126, 27-37.

29 H. Nasser Abdelhamid and H. F. Wu, Talanta, 2013, 115, 442-450.

30 S. Sun and H. Zeng, J. Am. Chem. Soc., 2002, 124, 8204-8205. 31 Q. A. Pankhurst, J. Connolly, S. K. Jones and J. Dobson, J. Phys. D: Appl. Phys., 2003, 36, R167-R181.

32 R. Yin, W. Guo, X. Zhou, H. Zheng, J. Du, Q. Wu, J. Chang and N. Ren, $R S C A d v$., 2016, 6, 19265-19270.

33 N. Atar, T. Eren, M. L. Yola, H. Karimi-Maleh and B. Demirdögen, $R S C A d v$. , 2015, 5, 26402-26409.

34 F. Yang, A. Feng, C. Wang, S. Dong, C. Chi, X. Jia, L. Zhang and Y. Li, RSC Adv., 2016, 6, 16911-16916.

35 G. A. O. Jinhao, G. U. Hongwei and X. U. Bing, Acc. Chem. Res., 2009, 42, 1097-1107.

36 S. C. N. Tang and I. M. C. Lo, Water Res., 2013, 47, 2613-2632.

37 J. H. Jung, J. H. Lee and S. Shinkai, Chem. Soc. Rev., 2011, 40, 4464.

38 H. N. Abdelhamid, Mater. Focus, 2016, 5, 305-323.

39 B. Tanhaei, A. Ayati, M. Lahtinen and M. Sillanpää, Chem. Eng. J., 2015, 259, 1-10.

40 S. Nasirimoghaddam, S. Zeinali and S. Sabbaghi, J. Ind. Eng. Chem., 2015, 27, 79-87.

41 Z. Taherimaslak, M. Amoli-Diva, M. Allahyari, K. Pourghazi and M. H. Manafi, RSC Adv., 2015, 5, 12747-12754.

42 F. Zare, M. Ghaedi and A. Daneshfar, Microchim. Acta, 2015, 182, 1893-1902.

43 X. Jiang, J. Cheng, H. Zhou, F. Li, W. Wu and K. Ding, Talanta, 2015, 141, 239-246.

44 A. Malekpour and M. Khodadadi, RSC Adv., 2016, 6, 1470514711.

45 L. Tang, Z. Xie, G. Zeng, H. Dong, C. Fan, Y. Zhou, J. Wang, Y. Deng, J. Wang and X. Wei, RSC Adv. , 2016, 6, 25724-25732.

46 X. Zhang, J. Wang, X. He, L. Chen and Y. Zhang, ACS Appl. Mater. Interfaces, 2015, 7, 24576-24584.

47 Y. Chen, Z. Xiong, L. Peng, Y. Gan, Y. Zhao, J. Shen, J. Qian, L. Zhang and W. Zhang, ACS Appl. Mater. Interfaces, 2015, 7, 16338-16347.

48 J. Gopal, H. N. Abdelhamid, P.-Y. Hua and H.-F. Wu, J. Mater. Chem. B, 2013, 1, 2463-2475.

49 H. N. Abdelhamid and H.-F. Wu, Mater. Sci. Eng., C, 2014, 45, 438-445.

50 M. L. Bhaisare, H. N. Abdelhamid, B.-S. Wu and H.-F. Wu, J. Mater. Chem. B, 2014, 2, 4671-4683.

51 H. N. Abdelhamid, S. Kumaran and H.-F. Wu, RSC Adv., 2016, 6, 97629-97635.

52 H. N. Abdelhamid, A. Talib and H.-F. Wu, RSC Adv., 2015, 5, 34594-34602.

53 H. N. Abdelhamid, Mater. Sci. Forum, 2015, 832, 28-53.

54 H. N. Abdelhamid and H.-F. Wu, J. Mater. Chem. B, 2013, 1, 3950-3961. 
55 I. García, M. Henriksen-Lacey, A. Sánchez-Iglesias, M. Grzelczak, S. Penadés and L. M. Liz-Marzán, J. Phys. Chem. Lett., 2015, 6, 2003-2008.
56 C. J. Park, S. H. Song, D. H. Kim and M. C. Gye, Aquat. Toxicol., 2016, 177, 446-453.

57 D. Joseph, S. Sachar, N. Kishore and S. Chandra, Colloids Surf., B, 2015, 135, 596-603. 